\title{
Seroprevalence of Hepatitis E Virus Infection and Factors Associated in HIV Infected Patients in Yaoundé (Cameroon)
}

\author{
Antonin Wilson Ndjitoyap Ndam ${ }^{*}$, Ousmanou Nsangou Mbombo Njoya ${ }^{1}$, Richard Njouom², \\ Mathurin Kowo ${ }^{1}$, Serge Clotaire Billong ${ }^{1}$, Firmin Ankouane ${ }^{1}$, Oudou Njoya ${ }^{1}$, \\ Elie Claude Ndjitoyap Ndam ${ }^{1}$
}

${ }^{1}$ Faculty of Medicine and Biomedical Sciences, University of Yaoundé I, Yaoundé, Cameroon

${ }^{2}$ Pasteur Center of Cameroon, Yaoundé, Cameroon

Email: `tonindam3@yahoo.fr, ousmanmbombonjya@gmail.com,njouom@pasteur-yaounde.org, kowomathurinp@yahoo.fr, sergebillong@yahoo.fr, ankouaneandoulo@yahoo.com,oudou_njoya@yahoo.fr, ecndam@yahoo.fr

How to cite this paper: Ndam, A.W.N., Njoya, O.N.M., Njouom, R., Kowo, M., Billong, S.C., Ankouane, F., Njoya, O. and Ndam, E.C.N. (2020) Seroprevalence of Hepatitis E Virus Infection and Factors Associated in HIV Infected Patients in Yaoundé (Cameroon). Open Journal of Gastroenterology, 10, 181-186.

https://doi.org/10.4236/ojgas.2020.107018

Received: April 25, 2020

Accepted: July 6, 2020

Published: July 9, 2020

Copyright $\odot 2020$ by author(s) and Scientific Research Publishing Inc. This work is licensed under the Creative Commons Attribution International License (CC BY 4.0).

http://creativecommons.org/licenses/by/4.0/

\section{(c) (i) Open Access}

\begin{abstract}
The Hepatitis E Virus (HEV) infection is one of the main causes of acute viral hepatitis. This affection is generally asymptomatic and benign. Its incidence is elevated in sub Saharan Africa. In Human Immunodeficiency Virus (HIV) infected patients, the HEV can cause chronic hepatitis with risks of cirrhosis and cancer. Assessing the prevalence and risk factors of an HEV infection in people living with HIV can help to prevent the transmission and the onset of their complications. The aim of this study was to evaluate the seroprevalence of HEV markers and associated factors among HIV infected patients in Yaoundé (Cameroon). Ninety HIV infected patients were included in this study, with 29 men (32.2\%) and 61 women (67.8\%). The mean age was $46 \pm$ 11.4 years old $(21-74)$. The prevalence of HEV serological markers was $6.7 \%$ and $12.2 \%$ for immunoglobulins (IgG) and IgM respectively. Both IgG and IgM were positive for 2 patients (2.2\%), while 15 patients (16.7\%) had at least one immunoglobin positive. The consumption of well water and porcine foods was found to be associated with the presence of IgM HEV antibodies. There was no association between CD4 count, viral load and the presence of HEV serological markers.
\end{abstract}

\section{Keywords}

Seroprevalence, Hepatitis E, HIV, Associated Factors, Yaoundé

\section{Introduction}

The Hepatitis E Virus (HEV) is widely expanded in the world. It has an esti- 
mated incidence of 20 billion each year [1]. The virus infects humans and animals such as pork and primates [2] [3]. A zoonotic transmission exists in humans through the consumption of porcine or monkeys foods, thought the consumption of the latter is prohibited [3] [4]. Contaminated water is also a route of transmission [2] [3] [5]. Low-incomes countries with poor hygiene conditions are most affected [6]. This infection is commonly benign and asymptomatic, with spontaneous healing in less than 6 months. But it can lead to a fulminant hepatitis with a risk of death in elderly patients and in pregnant women [7] [8]. Studies done in the West seem to show that in Human Immunodeficiency Virus (HIV) infected patients, the HEV infection can cause a chronic hepatitis and favor the onset of complications such as cirrhosis and liver cancer [6] [9] [10]. Thus, HEV and HIV coinfection could be a poor prognosis factor in patients living with HIV. Some studies have been done in Central Africa to access the prevalence of HEV antibodies among HIV infected patients. Feldt and Modiyinji obtained $14.2 \%$ and $8.5 \%$ respectively of anti-HEV Immunoglobulins (IgG) in Cameroon in 2019, Bivigou-Mboumba obtained a seroprevalence 3.5\% in Franceville (Gabon) in 2017, and Demi Sibiro obtained 68\% of IgG in Central African Republic in 2018 [7] [8] [11] [12]. Assessing the prevalence and identifying risk factors of HEV infection in patients living with HIV can help to prevent their transmission, and the onset of complications. The aim of this study was to evaluate the prevalence and associated factors with the presence of HEV antibodies in HIV infected patients in Yaoundé (Cameroon).

\section{Methodology}

We conducted a cross sectional descriptive study in the care and treatment center of persons living with HIV at the Yaoundé Central Hospital (Cameroon) over a period of 3 months (February to April 2019). We conveniently included all patients aged above fifteen living with HIV infection who gave their oral consent and who came for their routine consultation during our period of recruitment. Using a questionnaire, we collected data concerning age, gender, area of residency, consumptions habits (well water, porcine food) and patient comorbidities. The last CD4 count and HIV viral load results which were less than three months old were equally recorded. Then samples of blood $(20 \mathrm{ml})$ each were collected, centrifuged and sent to the virology unit of the national laboratory Pasteur Center of Cameroon. Concerning the HEV, we have looked for the presence of IgG and Ig M determined through the Elisa method using the immunologic test MP DIAGNOSTIC ${ }^{\circledR}$ 3.0. The result could be positive, negative or undetermined. A cut-off of 0.4 was considered positive for IgM while a cut-off of 0.5 positive for IgG. In case of undetermined result, the patient was excluded. Data was analyzed using SPSS version 20.0. Fisher's exact test and Chi 2 test were used to determine factors associated with the presence of HEV antibodies and a $p$ value $<0.05$ was considered statistically significant. The ethical committee of the Faculty of Medicine and Biomedical Sciences of the University of Yaoundé I gave its approval for this study, and we obtained the administrative 
authorization of the Yaoundé Central Hospital.

\section{Results}

A total of 90 patients were included, with 29 men (32.2\%) and 61 women (67.8\%). The mean age was $46 \pm 11.4$ years old $(21-74)$. Most of them $(72.2 \%)$ were leaving in urban areas. With respect to consumption habits, 24 patients (26.7\%) were eating porcine food, 30 patients (33.3\%) were drinking well water. Concerning comorbidities, 3 patients (3.3\%) also had hypertension, 2 (2.2\%) had diabetes, and 3 patients (3.3\%) were under treatment of tuberculosis. All our patients were taking the antiretroviral treatment as recommended by national guidelines. Sixty-nine patients (76.7\%) had a CD4 count greater than 200 cells per $\mathrm{mm}^{3}$. The HIV viral load was undetectable for 68 patients (75.6\%). IgG antibodies were positive for 6 patients (6.7\%) while Ig M antibodies were positive for 11 patients (12.2\%). Both IgG and IgM were positive for 2 patients (2.2\%), while 15 patients (16.7\%) had at least one immunoglobin positive. Factors associated with the presence of IgM HEV antibodies were the consumption of well water $(\mathrm{OR}=4.3 ; \mathrm{p}=0.031)$ and the consumption of porcine food $(\mathrm{OR}=2.5 ; \mathrm{p}=$ 0.041) (Table 1). We didn't find any association between CD4 count, HIV viral load and the presence of HEV antibodies (Table 1).

\section{Discussion}

The mean age of our HIV infected population was 44 years old. This age is relatively elevated due to the efficacy of the antiretroviral treatment against HIV. The antiretroviral treatment significantly increases the life expectancy with the infection. Studies have also shown that the prevalence of HEV markers increases significantly with age [7] [13]. Thus, an elevated mean age could explain a significant prevalence of the HEV immunoglobulins in our population. The infection is generally asymptomatic. Thus, a normal clinical exam does not exclude the possibility of the presence of the HEV.

Our results have showed that $16.7 \%$ of HIV infected patients had already been infected by the HEV. This percentage is low but not negligible regarding previous studies in Africa. Bivigou-Mboumba in Gabon in 2017 found a seroprevalence of $3.5 \%$ among 762 adults infected with HIV-1 [11]. Feldt obtained a

Table 1. Factors associated with the presence of HEV serological markers IgM.

\begin{tabular}{cccc}
\hline Parameters & Odds ratio & Confidence interval & p value \\
\hline Male sex & 0.6 & $0.1-2.3$ & 0.385 \\
Age $<$ 40 years & 1.7 & $0.5-6.2$ & 0.108 \\
Consumption of well water & 4.3 & $1.2-17.6$ & 0.031 \\
Consumption of porcine food & 2.5 & $1.3-7.5$ & 0.041 \\
CD4 count $<$ 200 & 0.7 & $0.1-3$ & 0.668 \\
HIV viral load undetectable & 1.5 & $0.4-10.6$ & 0.608 \\
\hline
\end{tabular}


prevalence of $14.2 \%$ anti-HEV IgG and IgM among 515 HIV infected patients [8]. Modiyinji obtained a prevalence of $7 \%$ anti-HEV IgM and $8.5 \%$ anti-HEV IgG among 270 HIV infected patients in Cameroon in 2019 [7]. Demi Sibiro et al. obtained a prevalence of $7.5 \%$ and $68 \%$ of anti-HEV IgM and IgG respectively in Central African Republic among 200 patients living with HIV in 2018 [12]. Our results are comparable to the results observed in previous studies. With the immunodeficiency due to the HIV infection, some of these patients could develop a chronic HEV [8] [9].

We found a significant association between the consumption of well water, which is supposed to be dirty, and the consumption of porcine food with the presence of IgM HEV antibodies. The consumption of these potentially infected water or porcine food can be the means of transmission for HEV. The association between dietary habits and the presence of HEV antibodies has been found in a prior study in the country without a significant value [7]. Some biological studies of these waters and foods should be done to better understand ways of the transmission of the HEV. The consumption of monkey's food is supposed to be prohibited, so this transmission cannot be assessed.

We didn't find any association between the CD4 count and HIV viral load with the presence of HEV antibodies, as previously observed by Ferreira in Brazil [14]. But, a low CD4 count has been found as a risk factor of unexplained persistant Alanine aminotransferase elevation in Switherland [6] [9]. These suggest that an immunodeficiency do not increase the risk of the presence of HEV serological markers, but increase the risk of evolution towards a chronic hepatitis $\mathrm{E}$ infection [13]. However, the onset of this ongoing infection is not common [11] [14]. The genotype of the HEV can play a major [8]. But we did not assess genotype in our study and thus constitutes a limit of this study.

Serological tests have showed evidences of recent or past infection by the HEV in our population. But the quantitative HEV RNA is necessary to look for the presence of the virus in the blood sample or not [14]. Looking our objectives, we did not realize this molecular analysis in our study.

\section{Conclusion}

The prevalence of immunoglobulins IgM and IgG of the HEV is low, but not negligible among HIV infected persons of the care center of Central Hospital in Yaoundé. The consumption of well water and/or the consumption of porcine food was significantly associated with the presence of IgM HEV antibodies. We didn't find any association between CD4 count and HIV viral load with the presence of HEV antibodies.

\section{Conflicts of Interest}

The authors declare they have no conflict interests.

\section{Funding}

We don't receive any funds for this research. 


\section{Ethical Consent}

The faculty of medicine and biomedical sciences of the University of Yaoundé I gave an ethical approval.

\section{References}

[1] Rein, D.B., Stevens, G.A., Theaker, J., Wittenborn, J.S. and Wiersma, S.T. (2012) The Global Burden of Hepatitis E Virus Genotypes 1 and 2 in 2005. Hepatology, 55, 988-997. https://doi.org/10.1002/hep.25505

[2] Kaba, M., Moal, V., Gérolami, R. and Colson, P. (2013) Epidemiology of Mammalian Hepatitis E Virus Infection. Intervirology, 56, 67-83.

https://doi.org/10.1159/000342301

[3] Modiyinji, A.F., Atsama, M.A., Chavely, G.A., Nola, M. and Njouom, R. (2019) Detection of Hepatitis E Virus Antibodies among Cercopithecidae and Hominidae Monkeys in Cameroon. Journal of Medical Primatology, 48, 364-366. https://doi.org/10.1111/jmp.12430

[4] Modiyinji, A.F., et al. (2020) Serological and Molecular Investigation of Hepatitis E Virus in Pigs Reservoirs from Cameroon reveals elevated Seroprevalence and Presence of Genotype 3. PLOS ONE, 15, e0229073. https://doi.org/10.1371/journal.pone.0229073

[5] Modiyinji, A.F., et al. (2019) Epidemiology of Hepatitis E Virus Infection in Animals in Africa: A Systematic Review and Meta-Analysis Protocol. Systematic Reviews, 8, Article No. 120. https://doi.org/10.1186/s13643-019-1038-0

[6] Dalton, H.R., Bendall, R., Ljaz, S. and Banks, M. (2008) Hepatitis E: An Emerging Infection in Developed Countries. Lancet Infection Diseases, 8, 698-709. https://doi.org/10.1016/S1473-3099(08)70255-X

[7] Modiyinji, A.F., Amougou-Atsama, M., Monamele, C.G., Nola, M. and Njouom, R. (2019) Seroprevalence of Hepatitis E Virus Antibodies in Different Human Populations of Cameroon. Journal of Medical Virology, 91, 1989-1994. https://doi.org/10.1002/jmv.25545

[8] Feldt, T., et al. (2013) Hepatitis E Virus Infections in HIV-Infected Patients in Ghana and Cameroon. Journal of Clinical Virology, 58, 18-23. https://doi.org/10.1016/j.jcv.2013.05.004

[9] Kenfak-Foguena, A., et al. (2011) Hepatitis E Virus Seroprevalence and Chronic Infections in Patients with HIV, Switzerland. Emerging Infectious Diseases, 17, 1074-1078. https://doi.org/10.3201/eid/1706.101067

[10] Amougou Atsama, M., et al. (2017) Hepatitis E Virus Infection as a Promoting factor for Hepatocellular Carcinoma in Cameroon: Preliminary Observations. International Journal of Infectious Diseases, 64, 4-8. https://doi.org/10.1016/j.ijid.2017.08.010

[11] Bivigou-Mboumba, B., et al. (2017) Hepatitis B, C, and E Infection among HIV-Infected Patients in Franceville, Gabon: Retrospective Cross-Sectional Study. Médecine et Santé Tropicales, 27, 274-280.

[12] Demi Sibiro, O.A., Manirakiza, A. and Komas, N.P. (2018) Seroprevalence of Hepatitis E Virus Infection among People Living With HIV in the Central African Republic. Open Forum Infectious Diseases, 5, ofy307. https://doi.org/10.1093/ofid/ofy307

[13] Politou, M., Boti, S., Androutsakos, T., Valsami, S., Pittaras, T. and Kapsimali, V. (2015) Seroprevalence of Hepatitis E in HIV Infected Patients in Greece. Journal of 
Medical Virology, 87, 1517-1520. https://doi.org/10.1002/jmv.24214

[14] Ferreira, A.C., Gomes-Gouvêa, M.C., Lisboa-Neto, G., Mendes-Correa, M.C.J., Picone, C.M., Salles, N.A., Mendrone-Junior, A., Carrilho, F.J. and Pinho, J.R.R. (2018) Serological and Molecular Markers of Hepatitis E Virus Infection in HIV-Infected Patients in Brazil. Archives of Virology, 163, 43-49.

https://doi.org/10.1007/s00705-017-3562-3 